\title{
NUTRICIÓN
}

\section{Factores que influyen en la inasistencia y abandono de embarazadas con bajo peso beneficiarias del Programa Alimentario Nutricional Integral (PANI)}

\author{
Laura Elizabeth González Céspedes', Silvia Stella Araujo Pino1, Susana \\ Sánchez Bernal', Macarena Morínigo'
}

\section{Resumen}

Introducción: En Paraguay, desde el 2005, existen de programas de asistencia nutricional, en ese entonces bajo en nombre de Programa Nacional de Asistencia Alimentario Nutricional (PROAN) y a partir del 2010 como Programa Alimentario Nutricional Integral (PANI). El programa tiene logros positivos en el estado nutricional, sin embargo, el porcentaje de deserción siguen siendo muy alta en esta sección de beneficiarios, por lo que resulta importante la elaboración de investigaciones cualitativas o cuantitativas que permitan identificar los motivos de inasistencia a los controles y así contribuir en la lucha por la erradicación de la desnutrición Contreras et al (2011), encontraron que la inasistencia al control era la causa principal de falta de adherencia programas nutricionales y concluyeron que existe la necesidad de reforzar en los controles de salud.

Con los resultados recolectados, se desea conocer los motivos, barreras y/o factores por el cual las mujeres no culminan con el programa, de forma que los datos sirvan como medidas correctivas y así contribuir en la lucha por la erradicación de la desnutrición, teniendo en cuenta la cantidad de fondos, que actualmente son insuficientes, destinados para la cobertura total de niños y embarazadas

La inversión gubernamental para la adquisición del complemento nutricional y los esfuerzos del sector salud para la distribución y entrega del mismo tendrían mejores resultados si se lograra un elevado porcentaje de retención y una baja deserción de embarazadas del programa.

Objetivo: Identificar los factores que influyen en la inasistencia y abandono de las embarazadas con bajo peso sujetos de derecho del Programa Alimentario Nutricional Integral (PANI).

Material y Método: Estudio cuali-cuantitativo, observacional descriptivo, en la que la población accesible fueron fichas de embarazadas con bajo peso que forman parte del PANI y cuyo ingreso se haya producido entre los meses de

1. Departamento de Nutrición. Dirección de Investigación. Facultad de Ciencias Químicas. Universidad Nacional de Asunción, Paraguay.

E-mail:mmorinigo@qui.una.py

DOI: 10.26885/rcei.foro.2017.107 
enero y diciembre del año 2015 en el Hospital de Limpio, a partir de las fichas se seleccionaron aquellos que cumplieron con los criterios de selección. La técnica empleada para la toma de datos fue el de focus grupo entre las usuarias, siendo ideal un tamaño de entre 5 a 7 integrantes. En cuanto a las variables, los datos de contacto, sociodemográficos y clínicos fueron extraídos de la ficha dela PANI y los motivos de inasistencia (medido a partir de pregunta abierta) y la actitud para reingresar al programa. De las 135 fichas revisadas en el periodo de estudio, el 45,2\% ( $n=65)$ no cumple con los 4 controles mínimos, de las mismas, 31/65 los datos de contactos no eran correctos, 29/65 solicitaron un nuevo contacto, luego no pudieron participar y solo 5/65 respondieron participaron del grupo de estudiar. La investigación contó con dictamen favorable del comité de ética Resultados: El promedio de edad de las mujeres beneficiarias fue de $20,7 \pm 4,96$ años y de escolaridad fue de $9,7 \pm 2,5$ años. Al evaluar si los factores socioeconómicos tales como, condición laboral, disponibilidad económica y redes sociales de apoyo, en la concurrencia a los controles, se encontró que las ex-usuarias refieren que "Se encontraba tiempo para ir" y que no encontraban dificultad para movilizarse hasta el hospital, sin embargo, las ex-usuarias realizaron algunas recomendaciones para el PANI, en caso de que se presentará la oportunidad de re-ingresar al programa,: mejorar el tiempo de espera, se pierde mucho tiempo; mejorar el producto y otra mantener la amabilidad del personal y finalmente Se encontró diferentes motivos por los cuales las madres que respondieron refirieron haber no asistido a retirar la leche, y las mismas refirieron: que "no necesitaba", "perdió el bebé"; "no le gusto el producto", "tuvo el bebé y subió de peso" y otra "no recordaba que tenía que retirar".

Discusión: El velar por el buen estado nutricional de la embarazada es muy importante, dado los problemas que puede ocasionar tanto a la madre como al recién nacido. Resultó llamativo que solo 2/5 madres conocieran sobre los efectos del peso materno sobre el peso de nacimiento del niño, ya que el crecimiento fetal es un fenómeno complejo multifactorial es influido predominantemente por la madre y el desarrollo uterino. El bajo peso al nacer presenta consecuencias deletéreas como trastornos del aprendizaje, alteraciones en el desarrollo psicomotor y de crecimiento y mayor riesgo de padecer enfermedades crónicas en la edad adulta. Una intervención oportuna y a tiempo durante el embarazo y los primeros años de vida, se busca una adecuada nutrición que se vincula directamente con el logro de los Objetivos de Desarrollo del Milenio (ODM).

El $54,8 \%$ de las fichas de las beneficiarias no cumplieron con los 4 controles que estipula el PANI para determinar adherencia refiere que el incumplimiento y el abandono a las consultas es un hecho frecuente en las instituciones de salud. Este abandono representa un costo económico alto en cualquier sistema de salud; además del efecto negativo que la deserción puede tener sobre la salud del paciente.

El éxito de un programa alimentario depende de la eficiencia en la planificación, 


\section{Programa Alimentario Nutricional Integral. González et al.}

gestión y ejecución del mismo, para ello es importante abarcar aspectos como contar con personal capacitado para el monitoreo y evaluación del programa de tal forma buscar optimizar recursos y corregir las deficiencias

Conclusión: la distancia o el traslado hasta el centro de expendio del completo al parecer no sería un motivo de inasistencia, sin embargo, el tiempo de espera, la falta de conocimiento hacia la importancia de suplemento, la amabilidad y la aceptabilidad del productos, fueron referidos como motivos de no asistencia a los controles y por ende de no consumo del suplemento.

Palabras clave: embarazadas, inasistencia, motivos, PANI.

\section{Referencias}

Araujo, S. (2014). Efecto de la implementación del Programa Alimentario Nutricional Integral (PANI) en embarazadas del departamento de Presidente Hayes periodo 2011. San Lorenzo: Facultad de Ciencias Químicas, UNA.

Balestena, J., Suárez, C. \& Balestena, S. (2001). Valoración nutricional de la gestante. Rev Cubana Obstet Ginecol, 27(2),165-71

Barker, D. (2012). Developmental origins of chronic disease. Public Health,126(3),185-189.

Contreras, M, A., Herrera, Y., Rodríguez, O. L., Pizarro Q, T. \& Atalah S, E. (2011). Aceptabilidad y consumo de una bebida láctea con omega-3 en embarazadas y nodrizas del programa nacional de alimentación complementaria. Rev. Chil. Nutr., 38(3), 313-320.

INAN. (2013). Situación de nutrición y alimentación. Paraguay 2000 - 2013. Documento Técnico. Asunción: INAN-MSPBS.

Ramírez, O. (2016). Evolución antropométrica de mujeres embarazadas y puerperas al tercer y sexto control post ingreso al programa alimentario nutricional integral del hospital materno infantil de limpio 2014-2015. San Lorenzo: Facultad de Ciencias Químicas, UNA.

Robles, M. (2011). Objetivos de desarrollo del milenio. Informe 2011. New York: Naciones Unidas. 